\title{
Effect of gonadal steroids and gamma-aminobutyric acid on LH release and dopamine expression and activity in the zona incerta in rats
}

\author{
V. Kalia, C. Fenske, D. R. Hole and C. A. Wilson* \\ Department of Obstetrics and Gynaecology, St George's Hospital Medical School, Cranmer Terrace, London SW17 ORE, UK
}

\begin{abstract}
A dopaminergic system in the zona incerta stimulates LH release and may mediate the positive feedback effects of the gonadal steroids on $\mathrm{LH}$ release. In this study the mechanisms by which steroids might increase dopamine activity in the zona incerta were investigated. In addition, experiments were conducted to determine whether the inhibitory effects of gamma-aminobutyric acid (GABA) on LH release in the zona incerta are due to suppression of dopamine activity in this area or conversely whether the stimulatory effects of dopamine on LH release are due to suppression of a tonic inhibitory GABAergic system. Ovariectomized rats were treated s.c. with oil, $5 \mu \mathrm{g}$ oestradiol benzoate or $5 \mu \mathrm{g}$ oestradiol benzoate followed $48 \mathrm{~h}$ later by $0.5 \mathrm{mg}$ progesterone, and killed $54 \mathrm{~h}$ after the oestradiol benzoate injection. At this time the LH concentrations were suppressed in the oestradiol benzoate group and increased in the group treated with oestradiol benzoate and progesterone. The ratio of tyrosine hydroxylase: $\beta$-actin mRNA in the zona incerta was significantly increased by the oestradiol benzoate treatment, but the addition of progesterone resulted in values similar to those in the control group. At the same time, the progesterone treatment increased tyrosine hydroxylase activity in the zona incerta as indicated by an increase in L-dihydroxyphenylalanine (L-DOPA) accumulation after $100 \mathrm{mg}$ 3-hydroxybenzylhydrazine hydrochloric acid (NSD1015) $\mathrm{kg}^{-1}$ and an increase in dopamine release as indicated by a increase in dihydroxyphenylacetic acid (DOPAC) concentrations (one of the major metabolites of dopamine). Ovariectomized rats treated with oestradiol benzoate plus progesterone were also injected i.p. with $75 \mathrm{mg}_{\text {gamma-acetylenic GABA kg}}{ }^{-1}$ (a GABA transaminase inhibitor) to increase GABA concentrations in the brain. This treatment had no effect on the ratio of tyrosine hydroxylase: $\beta$-actin mRNA but decreased L-DOPA accumulation and DOPAC concentrations in the zona incerta, indicating a post-translational inhibition of dopamine synthesis and release. Treatment of ovariectomized rats with oestradiol benzoate followed by $100 \mathrm{mg}$ L-DOPA i.p. to increase dopamine concentrations in the whole brain had no effect on glutamic acid decarboxylase mRNA expression in the zona incerta, although it increased the glutamic acid decarboxylase: $\beta$-actin mRNA ratio in other hypothalamic areas (that is, the medial preoptic area, ventromedial nucleus and arcuate nucleus). In conclusion, the steroids act to increase dopamine activity in different ways: oestrogen increases tyrosine hydroxylase mRNA expression and progesterone acts after translation to increase tyrosine hydroxylase activity and dopamine release (as indicated by increases in DOPAC concentrations). This latter effect may be due to progesterone removing a tonic GABAergic inhibition from the dopaminergic system.
\end{abstract}

\section{Introduction}

The zona incerta situated in the dorsal hypothalamus is an important integrating centre, receiving and conveying neuronal tracts from the spinal cord, mid-brain, thalamus,

${ }^{*}$ Correspondence.

Received 25 November 1998 cortex and limbic system (Ricardo, 1981; Eaton et al., 1994; Mihailoff, 1995; Nicolelis et al., 1995; Moga and Moore, 1996; Shammagh-Lagnado et al., 1996). The zona incerta is involved in a number of physiological processes such as sleep-waking cycles, ingestive behaviour, motor activity, visual perception, eye movement and nociceptive response (Kaelber and Smith, 1979; Legg, 1979; Dalton and Grossman, 1982; Kendrick and Baldwin, 1986; Tonelli and Chiaraviglio, 
1995; May et al., 1997). Oestrogen receptors (of both the $\alpha$ and $\beta$ type) are present in the zona incerta (Sar, 1984; Shrughrue et al., 1997) as are steroid metabolizing enzymes (Haglund et al., 1984), and this area regulates steroid-dependent functions such as gonadotrophin release (MacKenzie et al., 1984; James et al., 1987; Sanghera et al., 1991a) and male and female sexual behaviour (Dornan et al., 1991; Wilson et al., 1991).

The zona incerta forms part of the dopaminergic incertohypothalamic tract that originates from three nuclear areas of dopamine cell bodies termed A11, A13 and A14 (Bjorklund and Nobin, 1973). The cell bodies of the A11 group are sited in the caudal thalamus and their terminals reach the medialanterior part of the zona incerta. The A13 group are present in the zona incerta close to these nerve terminals and immunocytological techniques reveal that their axons lead to various hypothalamic nuclei, that is, the dorsal medial nucleus, paraventricular nucleus, lateral hypothalamus and anterior hypothalamus (Bjorklund and Nobin, 1973; Bjorklund et al., 1975). There is controversy as to whether the preoptic area is innervated by dopamine neurones from the zona incerta (Bjorklund et al., 1975; Day et al., 1980), but if they are present, they do not impinge on GnRH neurones (Horvath et al., 1993). The anterograde tracer technique shows that neurones in the zona incerta project ipsilaterally to the paraventricular nucleus, anterior hypothalamus, ventromedial nucleus, supraoptic nucleus, arcuate nucleus and medial preoptic area (Wagner et al., 1995), but these are not necessarily dopaminergic and may belong to other neuronal systems originating in the zona incerta; examples include gamma-aminobutyric acid (GABA) (Oertel et al., 1982), adrenaline (Ross et al., 1984), aspartate (Moga and Moore, 1996), melanin concentrating hormone (MCH) (Bittencourt et al., 1992) and orexin (Sakurai et al., 1998).

The dopamine system in the zona incerta exerts a stimulatory effect on the secretion of $\mathrm{LH}$, since application of dopamine into the zona incerta stimulates LH release, whereas dopamine antagonists have the opposite effect (MacKenzie et al., 1984; James et al., 1987). This action is probably of physiological significance, since selective lesions of the dopaminergic nerve terminals in the zona incerta and lesions of all the cell bodies in this area prevent normal oestrous cyclicity (MacKenzie et al., 1984, 1988) and electrolytic lesions prevent the pro-oestrous preovulatory LH surge (Sanghera $e t$ al., 1991a) and decrease concentrations of GnRH in the median eminence (Wilkes et al., 1979). Conversely, dopamine turnover in the zona incerta increases at the time of the preovulatory LH surge in intact female rats and the $\mathrm{LH}$ surge induced by ovarian steroids in ovariectomized rats (MacKenzie et al., 1988; Wilson et al., 1991).

GABA neurones in the zona incerta also regulate $\mathrm{LH}$ release. Administration of GABA agonists into the zona incerta results in inhibition of LH release, whereas antagonists have the opposite effect (Wilson et al., 1990). Furthermore, ovarian steroid treatment reduces the expression of the rate-limiting synthetic enzyme glutamic acid decarboxylase (GAD) in the zona incerta at the time of the expected increase in LH secretion (Leigh et al., 1990).

The observations that administration of oestradiol benzoate and progesterone to ovariectomized rats can alter dopamine turnover and glutamic acid decarboxylase mRNA expression in the zona incerta at the same time as stimulating release of LH indicate that dopamine and GABA may mediate ovarian steroid regulation of the cyclical release of LH. The aim of the present study was to elucidate the mechanisms by which the steroids might alter dopaminergic activity in the zona incerta and to determine whether their effects are exerted on mRNA expression or posttranslationally or on other events along the pathway. In addition, the possible interaction between the dopaminergic and GABAergic systems in the zona incerta was investigated. Whole brain GABA concentrations were increased and any changes in dopamine activity in the zona incerta were recorded. Conversely, whole brain dopamine concentrations were increased and changes in glutamic acid decarboxylase mRNA expression were measured. The modulation of these possible interactions by ovarian steroids was considered.

\section{Materials and Methods}

\section{Animals}

Female Wistar rats (180-220 g) bred at St George's Hospital Medical School were ovariectomized under halothane (Fluothane, Zeneca Ltd, Macclesfield) and nitrous oxide anaesthesia and allowed to recover for at least 2 weeks before experimentation. The rats were housed in groups of five in a fixed lighting system (lights on 07:00 h to 19:00 h) and given food and water ad libitum.

\section{General procedures and treatments}

There were three treatment groups in each experiment and treatment was initiated at 12:00 h. Rats were treated s.c. with either $0.1 \mathrm{ml}$ corn oil, $5 \mu \mathrm{g}$ oestradiol benzoate in $0.1 \mathrm{ml}$ oil, or $5 \mu \mathrm{g}$ oestradiol benzoate followed $48 \mathrm{~h}$ later by either $0.1 \mathrm{ml}$ oil or $0.5 \mathrm{mg}$ progesterone in $0.1 \mathrm{ml}$ oil. At $6 \mathrm{~h}$ after progesterone or $54 \mathrm{~h}$ after the first injection of oil or oestradiol benzoate, the animals were decapitated. Blood was collected from the cervical cut and the brain was removed, placed immediately in solid $\mathrm{CO}_{2}$, and stored at $-80^{\circ} \mathrm{C}$ or frozen in liquid nitrogen-cooled isopentane for subsequent mRNA extraction. The blood samples were centrifuged at $400 \mathrm{~g}$ at $4^{\circ} \mathrm{C}$ for $15 \mathrm{~min}$ and the plasma was stored at $-20^{\circ} \mathrm{C}$ until assayed for $\mathrm{LH}$.

In one experiment, groups of ovariectomized rats were treated with oestradiol benzoate alone and killed at $0,6,24$, $30,48,51$ or $54 \mathrm{~h}$ after the oestradiol benzoate injection (that is, at 12:00 or $18: 00 \mathrm{~h}$ on day $1,12: 00$ or $18: 00 \mathrm{~h}$ on day 2 and $12: 00,15: 00$ or $18: 00 \mathrm{~h}$ on day 3 ). Groups of oil-treated rats were killed at 12:00, 15:00 and 18.00 h to serve as controls for a possible circadian rhythm.

Other treatments included 3-hydroxybenzylhydrazine hydrochloric acid (NSD1015, $100 \mathrm{mg} \mathrm{kg}^{-1}$ i.p.; Sigma Chemical Co. Ltd, Poole), an aromatic-acid decarboxylase inhibitor, administered $20 \mathrm{~min}$ before the animals were killed. This time was chosen after determination of the rate of 
accumulation of L-3,4-dihydroxyphenylalanine (L-DOPA) in the zona incerta during 10-60 min after NSD1015, which showed that accumulation reached a plateau only after 30 min. The GABA transaminase inhibitor, gamma-acetylenic GABA (GAG; Merrell Dow Labs, Strasbourg) was administered ( $75 \mathrm{mg} \mathrm{kg}^{-1}$ i.p.) $1 \mathrm{~h}$ after progesterone, that is $5 \mathrm{~h}$ before the rats were killed. The dopamine precursor L-DOPA (Sigma Chemical Co. Ltd, Poole) was administered (100 mg kg-1 i.p.) to the oestradiol benzoate-treated group at $60 \mathrm{~min}$ before the rats were killed, to raise whole brain concentrations of dopamine.

\section{Preparation of brain samples for analysis}

Microdissection of the zona incerta was carried out according to the method of Palkovits (1973) using a flattipped needle of $0.7 \mathrm{~mm}$ diameter as the punch. Other areas were dissected at the same time, including the preoptic area, ventromedial nucleus and arcuate nucleus; all sites were identified according to Paxinos and Watson (1982). Samples were stored at $-80^{\circ} \mathrm{C}$ until analysed for amines within 4 weeks. In the case of mRNA assessment, RNA extraction was carried out immediately after the microdissection.

\section{HPLC and electrochemical detection}

Dopamine and dihydroxyphenylacetic acid (DOPAC). The micropunch samples were sonicated in cold $0.1 \mathrm{~mol}$ perchloric acid $\mathrm{l}^{-1}$ (HPLC grade; Merck, Lutterworth) containing $0.01 \mu \mathrm{g}$ isoprenaline as the internal standard. After centrifuging at $11000 \mathrm{~g}$ for $15 \mathrm{~min}, 50 \mu \mathrm{l}$ supernatant was injected via a Rheodyne 7125 injection valve into a Beckman ultrasphere ion-pair $5 \mu \mathrm{m}$ column $(15 \mathrm{~cm} \times 4.6 \mathrm{~mm})$ protected by a guard column (Uptight Pre-column Kit-C135 $\beta$; Jones Chromatograph Ltd, Hengoed). The dopamine and DOPAC were detected using an LC4C amperometric detector (BAS Technicol Ltd, Congleton) set in oxidative mode with a potential of $+0.7 \mathrm{~V}$ versus an $\mathrm{Ag}-\mathrm{AgCl}$ reference electrode (Model TL5A; BAS Technicol). The mobile phase consisted of filtered and de-gassed $0.1 \mathrm{~mol}$ citric acetate $\mathrm{l}^{-1}, 25 \mathrm{mmol} \mathrm{NaOH} \mathrm{l}^{-1}$ and $1 \mathrm{mmol}$ EDTA-Na l-1 (pH 3.55) containing $0.5 \mathrm{mmol}$ octane sulphonate $\mathrm{l}^{-1}$ as the ion-pair reagent and $6 \%(\mathrm{v} / \mathrm{v})$ acetonitrile.

Chromatograms were analysed by a Schimadzu CR3A Chromatopac integrator (Shimadzu UK, Milton Keynes) and the sensitivity was $10-15 \mathrm{pg}$ for dopamine and DOPAC dependent upon laboratory conditions. Protein content was estimated on the remaining pellet after extraction with perchloric acid, using the modified Coomassie blue method of Bradford (1976).

$L$-DOPA. All details were as described above except the mobile phase consisted of $0.1 \mathrm{~mol}$ citric acetate buffer $\mathrm{l}^{-1}$ at pH 4.85 containing 1.1 mmol heptane sulphonate $\mathrm{l}^{-1}$ and $3 \%$ methanol. The internal standard was dihydroxyphenylglycol (Sigma Chemical Co. Ltd, Poole). The L-DOPA was detected by the Coulochem electrochemical detection (ESA Analytical, St Ives, Huntingdon) and the chromatograms were analysed by a Spectra-Physics SP4270 integrator (Thermo Separation Products, Stone). The sensitivity for L-DOPA was 25 pg.

\section{RNA extraction and slot-blot analysis of tyrosine hydroxylase, glutamic acid decarboxylase and $\beta$-actin mRNAs}

Total RNA was extracted from individual micropunch samples using RNAzol B (Biogenics Ltd, Bournemouth) according to the manufacturer's protocol. The quality of the extracted RNA was assessed by standard northern blotting procedures using glyoxal to denature the RNA and $\left.{ }^{32} \mathrm{P}\right] \mathrm{d}-$ CTP-labelled (Amersham International, Amersham) tyrosine hydroxylase cDNA (Tufts University, Boston, USA), glutamic acid decarboxylase $67 \mathrm{cDNA}$ (UCLA, USA) or $\beta$-actin (Galton Laboratories, University College London; used as a 'house-keeping' gene) as the probes. The signal obtained from autoradiography was discrete, indicating undegraded RNA, and the size of the mRNA molecule hybridized with the relevant probe corresponded to published values (Leigh et al., 1990; Lewis et al., 1983).

The RNA derived from each micropunch sample was applied in $100 \mu \mathrm{l}$ sterile water to a nylon membrane (Zetaprobe; Bio-Rad, Hercules, CA) using a manifold slotblot apparatus (Schleicher \& Schuell, Dassel). The filters were baked at $80^{\circ} \mathrm{C}$ for $1 \mathrm{~h}$ to fix the RNA, prehybridized and then hybridized overnight at $42^{\circ} \mathrm{C}$ with either [ $\left.{ }^{32} \mathrm{P}\right] \mathrm{d}$-CTPlabelled tyrosine hydroxylase cDNA or glutamic acid decarboxylase $67 \mathrm{cDNA}$. For rehybridization, the probes were stripped off the filter by washing in boiling $0.1 \times \mathrm{SSC}$ (saline sodium citrate) $-0.1 \% \quad(\mathrm{w} / \mathrm{v})$ SDS and cooling gradually to room temperature. The filter was subjected to autoradiography to ensure that all the probe had been removed. After prehybridization, the filter was rehybridized with $\left[{ }^{32} \mathrm{P}\right] \mathrm{d}$-CTP-labelled $\beta$-actin.

The filters were washed with solutions containing SSC and SDS. The stringency of washing was increased gradually by decreasing the SSC concentration and increasing the temperature; the final wash was carried out using $0.1 \times$ SSC $-0.1 \%(\mathrm{w} / \mathrm{v})$ SDS at $60^{\circ} \mathrm{C}$ for $5 \mathrm{~min}$. The filters were subjected to autoradiography with X-0mat-AR X-ray film for periods of up to 2 weeks. The film was developed using Kodak developer and fixer. The intensity of the bands obtained after autoradiography was measured using a scanning densitometer (Chromoscan 3; Joyce Loebl, Gateshead). Results were expressed as a ratio of peak intensity obtained after hybridization with tyrosine hydroxylase cDNA probe: $\beta$-actin cDNA probe or glutamic acid decarboxylase $67 \mathrm{cDNA}$ probe: $\beta$-actin cDNA probe.

\section{Radioimmunoassay for plasma $\mathrm{LH}$}

The assay was conducted according to Kendle et al. (1978). Plasma samples $(10 \mu \mathrm{l})$ were assayed in duplicate using reagents supplied by the National Hormone and Pituitary Program (Baltimore, MD). The standard was NIADDK-rLHRP3 and the antibody NIADDK-anti-rLH S10. The inter- and 
intra-assay coefficients of variation were 8.0 and $9.5 \%$, respectively, and the sensitivity was $10 \mathrm{pg}$ per tube (1 $\mathrm{ng} \mathrm{ml}^{-1}$ ).

\section{Statistical analysis}

The significance of difference between two groups was assessed by the Student's $t$ test together with their $95 \%$ confidence limits. Comparisons among more than two groups were carried out by ANOVA followed by Gabriel's test for comparison of unequal groups.

\section{Results}

\section{Effect of steroids on dopamine activity in the zona incerta}

Expression of tyrosine hydroxylase mRNA in the zona incerta. Ovariectomized rats were treated with either $5 \mu \mathrm{g}$ oestradiol benzoate, which reduced $\mathrm{LH}$ release as noted $54 \mathrm{~h}$ later, or $5 \mu \mathrm{g}$ oestradiol benzoate followed at $48 \mathrm{~h}$ by $0.5 \mathrm{mg}$ progesterone, which stimulated LH release (Table 1). At this time, slot-blot analysis of micropunch samples of the zona incerta showed that the expression of mRNA for tyrosine hydroxylase, the rate-limiting enzyme for catecholamines, was significantly increased by treatment with oestradiol benzoate alone. This was indicated by the ratio of tyrosine hydroxylase: $\beta$-actin mRNA compared with that in the oiltreated animals. Administration of progesterone to the oestradiol benzoate-treated animals decreased the ratio to a value similar to that in the controls.

The tyrosine hydroxylase: $\beta$-actin $\mathrm{mRNA}$ ratio at several intervals after the oestradiol benzoate treatment is shown (Table 2); only the value at $54 \mathrm{~h}$ after injection was significantly higher in the oestradiol benzoate-treated animals than in the controls.

Effect on tyrosine hydroxylase activity. Ovariectomized rats primed with either oil, oestradiol benzoate alone or oestradiol benzoate plus progesterone were all treated i.p. with $100 \mathrm{mg} \mathrm{NSD} 1015 \mathrm{~kg}^{-1}$ at $20 \mathrm{~min}$ before the animals were killed. NSD1015 is an aromatic-acid decarboxylase inhibitor and prevents the conversion of L-DOPA to dopamine. Thus the accumulation of L-DOPA in the $20 \mathrm{~min}$ after the NSD1015 injection is an indication of tyrosine hydroxylase activity (that is, in converting tyrosine to L-DOPA). Treatment with oestradiol benzoate alone had no effect on L-DOPA accumulation, but oestradiol benzoate plus progesterone at the time of increased LH release significantly increased L-DOPA concentrations, indicating an increase in tyrosine hydroxylase activity (Table 3).

Table 1. Effect of gonadal steroids and increased gamma-aminobutyric acid (GABA) concentrations on the ratio of tyrosine hydroxylase: $\beta$-actin mRNA in the zona incerta in female ovariectomized rats

\begin{tabular}{|c|c|c|c|c|}
\hline & \multicolumn{4}{|c|}{ Steroid treatment } \\
\hline Tyrosine hydroxylase: $\beta$-actin mRNA & $0.87 \pm 0.16(7)$ & $2.72 \pm 0.48^{* *}(6)$ & $1.00 \pm 0.17(7)$ & $1.63 \pm 0.09(6)$ \\
\hline Plasma LH (ng ml-1) & $7.50 \pm 0.43(7)$ & $3.43 \pm 1.05^{*}(6)$ & $42.64 \pm 6.39^{* *+}(6)$ & $14.90 \pm 0.45^{\ddagger}(12)$ \\
\hline
\end{tabular}

Ovariectomized rats were injected s.c. with $0.1 \mathrm{ml}$ oil, $5 \mu \mathrm{g}$ oestradiol benzoate or $5 \mu \mathrm{g}$ oestradiol benzoate followed $48 \mathrm{~h}$ later by $0.1 \mathrm{ml}$ oil or $0.5 \mathrm{mg}$ progesterone. The progesterone-treated animals were also injected i.p. with $1 \mathrm{ml}$ saline $\mathrm{kg}^{-1}$ or $75 \mathrm{mg}$ gamma-acetylenic GABA kg-1 (GAG; gamma-acetylenic GABA; GABA T inhibitor) at $1 \mathrm{~h}$ after the progesterone treatment. All animals were killed $54 \mathrm{~h}$ after oestradiol benzoate, that is, $6 \mathrm{~h}$ after progesterone and $5 \mathrm{~h}$ after $\mathrm{GAG}$. Values are mean \pm SE. Numbers in parentheses represent number of micropunch samples or plasma samples in each group.

${ }^{*} P<0.01,{ }^{*} P<0.001$ compared with oil-treated controls; ${ }^{\dagger} P<0.001$ compared with groups treated with oestradiol benzoate alone; $t P<0.001$ compared with oestradiol benzoate + progesterone group (ANOVA and Gabriel's test for multiple comparison).

Table 2. Changes in the ratio of tyrosine hydroxylase: $\beta$-actin mRNA in the zona incerta after administration of $5 \mu \mathrm{g}$ oestradiol benzoate in female ovariectomized rats

Time after oestradiol benzoate administration

\begin{tabular}{|c|c|c|c|c|c|c|c|}
\hline Treatment & $\begin{array}{c}0 \mathrm{~h} \\
\text { (Day 1: } 12: 00 \mathrm{~h})\end{array}$ & $\begin{array}{c}6 \mathrm{~h} \\
\text { (Day 1: 18:00 h) }\end{array}$ & $\begin{array}{c}24 \mathrm{~h} \\
\text { (Day 2: } 12: 00 \mathrm{~h} \text { ) }\end{array}$ & $\begin{array}{c}30 \mathrm{~h} \\
\text { (Day 2: 18:00 h) }\end{array}$ & $\begin{array}{c}48 \mathrm{~h} \\
\text { (Day 3: 12:00 h) }\end{array}$ & $\begin{array}{c}51 \mathrm{~h} \\
\text { (Day 3: 15:00 h) }\end{array}$ & $\begin{array}{c}54 \mathrm{~h} \\
\text { (Day 3: 18:00 h) }\end{array}$ \\
\hline $\begin{array}{l}\text { Ratio tyrosine } \\
\text { hydroxylase: } \\
\beta \text {-actin mRNA (oil) }\end{array}$ & $0.64 \pm 0.07(6)$ & $0.74 \pm 0.09(15)$ & $0.64 \pm 0.07(6)$ & $0.74 \pm 0.09$ & $0.64 \pm 0.07(6)$ & $0.74 \pm 0.20(3)$ & $0.74 \pm 0.09(15)$ \\
\hline $\begin{array}{l}\text { Ratio tyrosine } \\
\text { hydroxylase: } \\
\beta \text {-actin mRNA } \\
\text { (oestradiol benzoate) }\end{array}$ & $0.65 \pm 0.08(5)$ & $0.97 \pm 0.27(5)$ & $0.92 \pm 0.12(4)$ & $0.48 \pm 0.09(6)$ & $0.48 \pm 0.11(7)$ & $0.87 \pm 0.25(4)$ & $1.65 \pm 0.23^{*+}(10)$ \\
\hline $\begin{array}{l}\text { Plasma LH }\left(\mathrm{ng} \mathrm{ml}^{-1}\right) \\
\text { (oestradiol benzoate) }\end{array}$ & $13.51 \pm 2.37^{\ddagger}(5)$ & $2.53 \pm 0.66(8)$ & $3.57 \pm 0.41(5)$ & $2.89 \pm 0.67(5)$ & $4.33 \pm 0.90(6)$ & $3.62 \pm 0.41(4)$ & $4.78 \pm 0.71(13)$ \\
\hline
\end{tabular}


Table 3. Effect of gonadal steroids and increased gamma-aminobutyric acid (GABA) concentrations on $\mathrm{L}$-dihydroxyphenylalanine (L-DOPA) accumulation in the zona incerta in female ovariectomized rats

\begin{tabular}{|c|c|c|c|c|}
\hline & \multicolumn{4}{|c|}{ Steroid treatment } \\
\hline aL-DOPA (pg $\mu g^{-1}$ protein) & $2.68 \pm 0.16(7)$ & $3.87 \pm 0.81(6)$ & $5.30 \pm 0.32^{* \dagger}(7)$ & $3.49 \pm 0.45^{\ddagger}(6)$ \\
\hline Plasma LH $\left(\mathrm{ng} \mathrm{ml}^{-1}\right)$ & $10.66 \pm 0.76(7)$ & $3.70 \pm 0.41^{* *}(7)$ & $20.41 \pm 5.44^{* *+}(4)$ & $1.97 \pm 0.28^{\ddagger \ddagger}(6)$ \\
\hline
\end{tabular}

Treatments were as for Table 1.

aL-DOPA: accumulation assessed $20 \mathrm{~min}$ after administration of $100 \mathrm{mg}$ 3-hydroxybenzylhydrazine hydrochloric acid (NSD1015) $\mathrm{kg}^{-1}$ i.p.

Values are mean \pm SE. Numbers in parentheses represent number of micropunch samples in each group.

${ }^{*} P<0.01,{ }^{* *} P<0.001$ compared with oil-treated controls; ${ }^{t} P<0.001$ compared with group treated with oestradiol benzoate alone; ${ }^{t} P<0.01, \neq \neq p<0.001$ compared

with oestradiol benzoate + progesterone + saline group (ANOVA and Gabriel's test for multiple comparison).

"Effect on dopamine and DOPAC concentrations. The concentrations of dopamine and one of its major metabolites DOPAC were measured in ovariectomized animals treated with oil, oestradiol benzoate alone or oestradiol benzoate plus progesterone. Oestradiol benzoate had no effect on the concentration of either dopamine or DOPAC, whereas in the animals treated with oestradiol benzoate plus progesterone, there was a significant increase in DOPAC concentrations at the time of the increased release of $\mathrm{LH}$; dopamine concentrations were not affected by the oestradiol benzoate plus progesterone treatment (Table 4).

\section{Effect of increasing whole brain GABA concentrations on dopaminergic activity in the zona incerta}

Ovariectomized animals primed with oestradiol benzoate plus progesterone were treated i.p. with either $0.1 \mathrm{ml}$ saline

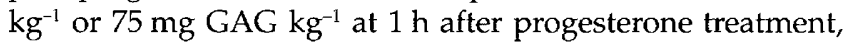
that is $5 \mathrm{~h}$ before the animals were killed. GAG is a GABA transaminase inhibitor and so increases endogenous GABA concentrations by preventing its degradation. Groups treated with oestradiol benzoate plus progesterone showed high concentrations of $\mathrm{LH}$, and GAG significantly reduced these

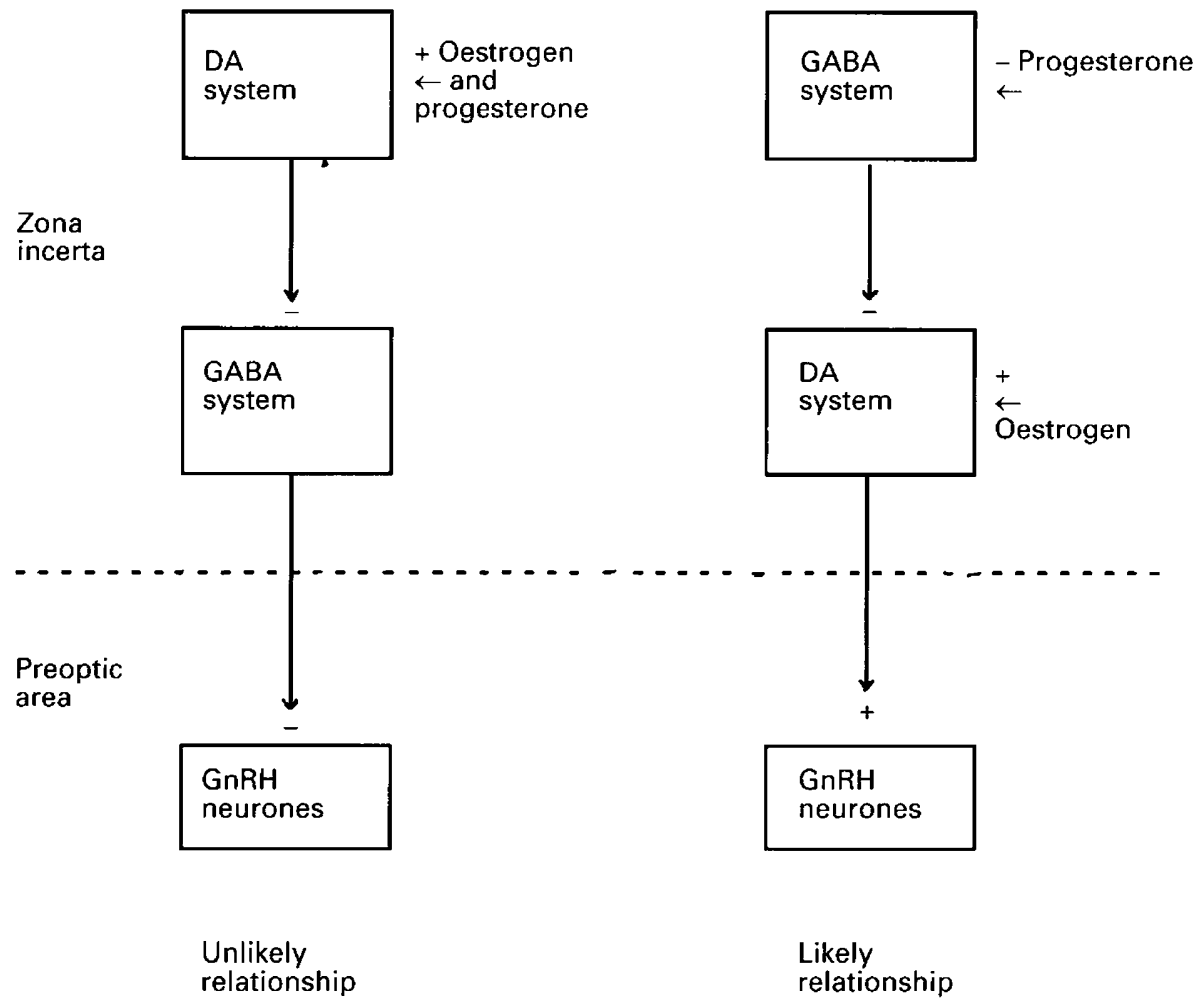

Fig. 1. The possible relationships between dopamine (DA) and gamma-aminobutyric acid (GABA) in the zona incerta and GnRH secretion. Other systems linking neuronal activity in the zona incerta with the GnRH neurones are probably present at the level depicted by the dotted line. + , indicates stimulatory effect; - , indicates inhibitory effect. 
Table 4. Effect of gonadal steroids and increased gamma-aminobutyric acid (GABA) concentrations on dopamine and dihydroxyphenylacetic acid (DOPAC) concentrations in the zona incerta in female ovariectomized rats

\begin{tabular}{|c|c|c|c|c|}
\hline & \multicolumn{4}{|c|}{ Steroid treatment } \\
\hline Dopamine (pg $\mu \mathrm{g}^{-1}$ protein) & $4.50 \pm 0.52(12)$ & $4.19 \pm 0.86(14)$ & $4.50 \pm 0.56(12)$ & $4.41 \pm 0.64(9)$ \\
\hline DOPAC (pg $\mu g^{-1}$ protein) & $1.52 \pm 0.24(7)$ & $1.18 \pm 0.12(12)$ & $2.40 \pm 0.39^{*+}(6)$ & $1.63 \pm 0.09 \ddagger(6)$ \\
\hline Plasma LH (ng ml $\left.{ }^{-1}\right)$ & $6.78 \pm 1.04(12)$ & $3.67 \pm 0.47^{*}(16)$ & $29.62 \pm 4.87^{* *+}(9)$ & $1.30 \pm 0.15^{\ddagger \ddagger}(5)$ \\
\hline
\end{tabular}

Treatments were as for Table 1.

Values are mean $\pm \mathrm{SE}$. Numbers in parentheses represent number in each group.

${ }^{*} P<0.01,{ }^{* *} P<0.001$ compared with oil-treated controls; ${ }^{t} P<0.001$ compared with group treated with oestradiol benzoate alone; ${ }^{\ddagger} P<0.01,{ }^{t \neq} P<0.001$ compared with oestradiol benzoate + progesterone + saline group (ANOVA and Gabriel's test for multiple comparison).

concentrations. GAG had no effect on the ratio of tyrosine hydroxylase: $\beta$-actin mRNA expression (Table 1$)$, whereas it significantly reduced L-DOPA accumulation and DOPAC concentrations in the zona incerta (Tables 3 and 4). The effect on DOPAC was specific to the zona incerta and did not occur in the other areas analysed (preoptic area, ventromedial nucleus and arcuate nucleus) (see Table 5). In addition, GAG treatment had no effect on L-DOPA accumulation in the arcuate nucleus and ventromedial nucleus, but did induce a decrease in L-DOPA in the preoptic area (Table 5).

\section{Effect of increasing whole brain dopamine concentrations on $G A D$ mRNA in hypothalamic areas}

Ovariectomized rats primed with $5 \mu \mathrm{g}$ oestradiol benzoate were injected i.p. with $100 \mathrm{mg} \mathrm{L-DOPA} \mathrm{kg} \mathrm{at}^{-1} \mathrm{~h}$ before the animals were killed. This treatment increased dopamine concentrations approximately threefold in the zona incerta, preoptic area, ventromedial nucleus and arcuate nucleus (for example, in the zona incerta, dopamine concentrations (pg $\mu \mathrm{g}^{-1}$ protein $\pm \mathrm{SE}(n)$ ): oestradiol benzoate + saline, $4.19 \pm 0.86$ (14); oestradiol benzoate + L-DOPA, $12.08 \pm 3.28$ (8); $P<0.001$ ), but did not significantly alter LH concentrations ( $\mathrm{LH}$ concentrations $\left(\mathrm{ng} \mathrm{ml}^{-1} \pm \mathrm{SE} \quad(n)\right.$ ): oestradiol benzoate + saline, $3.7 \pm 0.47 \quad(16) ;$ oestradiol benzoate + L-DOPA, $3.8 \pm 1.06(8))$. The L-DOPA treatment increased GAD: $\beta$-actin ratios to a similar extent in all areas examined, that is, there was an increase of between 1.52- and 2.07-fold in the four areas, which are all within the $95 \%$ confidence limits of each group. In comparison with the relevant saline groups, the increase was significant in all areas, except the zona incerta (Table 6).

\section{Discussion}

Other studies showed that administration of dopamine into the zona incerta stimulates $\mathrm{LH}$ release, whereas dopamine antagonists have the opposite effect (MacKenzie et al., 1984;

Table 5. Effect of gonadal steroids and increased gamma-aminobutyric acid (GABA) concentrations on dopamine and dihydroxyphenylacetic acid (DOPAC) concentrations and L-dihydroxyphenylalanine (L-DOPA) accumulation in the preoptic area, ventromedial nucleus and arcuate nucleus in female ovariectomized rats

\begin{tabular}{llcr}
\hline Area of brain & & $\begin{array}{l}\text { Oestradiol benzoate }+ \\
\text { progesterone }+ \text { saline }\end{array}$ & $\begin{array}{r}\text { Oestradiol benzoate } \\
\text { progesterone }+ \text { GAG }\end{array}$ \\
\hline Preoptic area & L-DOPA & $5.52 \pm 0.51(6)$ & $3.75 \pm 0.29^{*}(7)$ \\
& Dopamine & $5.38 \pm 0.65(14)$ & $7.99 \pm 1.28(8)$ \\
Arcuate nucleus & DOPAC & $2.98 \pm 0.36(16)$ & $2.53 \pm 0.16(8)$ \\
& L-DOPA & $3.83 \pm 0.62(7)$ & $4.37 \pm 0.49(6)$ \\
Ventromedial nucleus & Dopamine & $9.02 \pm 1.97(13)$ & $12.70 \pm 3.25(8)$ \\
& DOPAC & $2.53 \pm 0.43(5)$ & $2.68 \pm 0.39(9)$ \\
& L-DOPA & $4.42 \pm 0.25(7)$ & $3.59 \pm 0.34(7)$ \\
& Dopamine & $5.14 \pm 0.70(16)$ & $5.72 \pm 0.85(9)$ \\
& DOPAC & $2.20 \pm 0.41(17)$ & $1.73 \pm 0.13(9)$
\end{tabular}

Ovariectomized rats were injected s.c. with $5 \mu \mathrm{g}$ oestradiol benzoate followed $48 \mathrm{~h}$ later with $0.5 \mathrm{mg}$ progesterone. At $1 \mathrm{~h}$ after progesterone the rats were injected

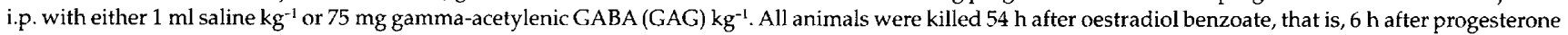
and $5 \mathrm{~h}$ after GAG. Some animals also received $100 \mathrm{mg}$ 3-hydroxybenzylhydrazine hydrochloric acid (NSD1015) $\mathrm{kg}^{-1}$ i.p. 20 min before they were killed to assess L-DOPA accumulation.

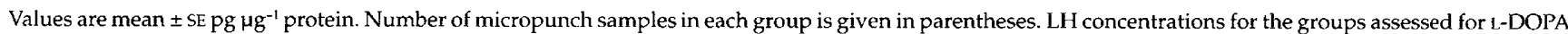
accumulation are shown in Table 3 and for groups assessed for dopamine and DOPAC in Table 4.

${ }^{*} P<0.01$ compared with group treated with oestradiol benzoate + progesterone + saline. 
Table 6. Effect of increased dopamine concentrations on ratio of glutamic acid decarboxylase (GAD): $\beta$-actin mRNA in hypothalamic areas in female ovariectomized rats

\begin{tabular}{|c|c|c|c|c|}
\hline \multirow[b]{2}{*}{ Hypothalamic area } & \multicolumn{2}{|c|}{ Ratio of GAD: $\beta$-actin mRNA: } & \multirow[b]{2}{*}{$\begin{array}{l}\text { Ratio of L-DOPA: } \\
\text { saline results }\end{array}$} & \multirow[b]{2}{*}{$95 \%$ confidence limits } \\
\hline & $\begin{array}{l}\text { Oestradiol benzoate } \\
\text { + saline }\end{array}$ & $\begin{array}{c}\text { Oestradiol benzoate } \\
+ \text { L-DOPA }\end{array}$ & & \\
\hline Zona incerta & $1.37 \pm 0.46(5)$ & $2.04 \pm 0.45(5)$ & 1.59 & $0.63-3.97$ \\
\hline Preoptic area & $1.24 \pm 0.18(6)$ & $1.82 \pm 0.20^{*}(9)$ & 1.52 & $1.03-2.23$ \\
\hline Ventromedial nucleus & $1.26 \pm 0.28(7)$ & $2.46 \pm 0.37^{*}(8)$ & 2.07 & $1.22-3.50$ \\
\hline
\end{tabular}

Ovariectomized rats were injected s.c. with $5 \mu \mathrm{g}$ oestradiol benzoate and either $1 \mathrm{ml} \mathrm{saline} \mathrm{kg}^{-1}$ or $100 \mathrm{mg} \mathrm{L}^{-D O P A ~ k g}{ }^{-1}$ (precursor of dopamine) was administered i.p. $1 \mathrm{~h}$ before the animals were killed at $54 \mathrm{~h}$ after oestradiol benzoate.

Values are mean $\pm \mathrm{SE}$. Numbers in parentheses represent number of micropunch samples in each group.

${ }^{*} P<0.05$ compared with group treated with oestradiol + saline (Student's $t$ test after log transformation for each area).

James et al., 1987). Furthermore, endogenous dopamine activity in the zona incerta is increased at the time of increased $\mathbf{L H}$ release as shown by a rise in turnover rate (assessed after inhibition of tyrosine hydroxylase by $\alpha$-methyl tyrosine), an increase in the ratio of DOPAC:dopamine and an increase in DOPAC concentrations (MacKenzie et al., 1988; Wilson et al., 1991). The concentration of DOPAC has been used as a marker of dopamine release, as it is the main metabolite of dopamine after dopamine is released from nerve terminals (Tian et al., 1991). These changes have been observed at the time of the preovulatory LH surge in intact females and also at the time of the LH surge induced in ovariectomized rats treated with oestradiol benzoate plus progesterone (MacKenzie et al., 1988; Wilson et al., 1991). Oestradiol benzoate alone, whether exerting a negative or positive feedback effect, has no effect on dopamine activity as assessed by the above parameters (Shoemaker and Schlumpf, 1977; Gunnet et al., 1986; Wilson et al., 1991). However, in long-term ovariectomized rats, chronic oestrogen treatment, either alone or with progesterone, restores the reduced immunoreactive tyrosine hydroxylase concentrations in dopamine neurones in the zona incerta to normal values (Sanghera et al., 1991b).

The aim of the present study was to determine the possible mechanisms by which the ovarian steroids might influence dopamine activity, that is, by affecting the expression or activity of the rate-limiting catecholamine synthetic enzyme tyrosine hydroxylase or by acting on the release of dopamine. The results showed that oestradiol benzoate alone increased expression of tyrosine hydroxylase mRNA $54 \mathrm{~h}$ after treatment, as indicated by the significant increase in the ratio of tyrosine hydroxylase: $\beta$-actin mRNA, whereas the oestradiol benzoate plus progesterone treatment reversed this increase. These results are in conflict with those of Morrell et al. (1989) who reported that steroid treatments had no influence on tyrosine hydroxylase mRNA (assessed by in situ hybridization) in the zona incerta. Although the steroid regimen was different from that used in the present study and no LH measurements were made when the animals were killed, Morrell et al. (1989) expected to see low LH concentrations in the group treated with oestradiol benzoate alone and an LH surge in the animals treated with oestradiol benzoate plus progesterone. The animals were killed at the mid-point of the dark phase in a $12 \mathrm{~h}$ light: $12 \mathrm{~h}$ dark regimen, whereas in the present study, animals were killed $1 \mathrm{~h}$ before the start of the dark period; this may explain the observed differences and emphasises the sensitivity of the kinetics of the system. In the present study, the LH surge was induced to occur at a time similar to the physiological timing of the natural LH surge (between 18:00 and 19:00 h, just before the transition from light to dark).

The results of the present study also showed that although progesterone appeared to reduce tyrosine hydroxylase mRNA in oestradiol benzoate-treated animals, at the same time it increased synthesis, as shown by the increase in L-DOPA accumulation, which is a marker of increased tyrosine hydroxylase activity. Progesterone also increased DOPAC concentrations, which could be interpreted as an increase in dopamine release (Tian et al., 1991) or an increase in degradative enzyme activity. Either explanation, when taken together with the increase in synthesis, indicates an increase in dopamine turnover and supports previous findings on dopamine turnover using $\alpha$-methyl tyrosine (MacKenzie et al., 1988; Wilson et al., 1991). The effect of oestradiol benzoate on tyrosine hydroxylase mRNA was observed at the time of reduced $\mathrm{LH}$ release, whereas the effect of progesterone on dopamine turnover was observed when LH was increased. The timing of the two effects might be different; the effect on tyrosine hydroxylase mRNA may precede translational events and any other events that occur further along the transmitter pathway. A time course of the effect of oestradiol benzoate on tyrosine hydroxylase mRNA showed that the increase does not occur earlier than $54 \mathrm{~h}$ after treatment and is not associated with any negative feedback effect on LH, which can be observed as early as $6 \mathrm{~h}$ after treatment. Thus, the stimulatory effect on expression of tyrosine hydroxylase mRNA may be in preparation for the potential positive feedback effect on $\mathrm{LH}$ release that occurs at a later stage and after any negative feedback effect, in the presence of sufficiently high concentrations of ovarian steroids. The post-translational effect of progesterone on tyrosine hydroxylase activity may have a feedback action to terminate further increased expression of tyrosine hydroxylase mRNA.

Oestradiol benzoate receptors are present in the nuclei of neurones in the zona incerta, whereas progesterone receptors have not been observed at that site (Sar, 1984; Fox et al., 1990). Downloaded from Bioscientifica.com at 04/26/2023 12:12:59PM 
Thus it is possible that oestradiol benzoate acts directly on dopaminergic cell bodies to affect tyrosine hydroxylase mRNA expression, whereas the effect of progesterone on the release of dopamine from nerve terminals (as indicated by the increase in DOPAC) may occur indirectly via another system. The focus of the present study was the possibility that progesterone induces this effect via a GABAergic system.

Progesterone treatment reduces GAD mRNA expression at the time of increased LH release in several hypothalamic areas, including the preoptic areas and zona incerta (Leigh et al., 1990; Unda et al., 1995). Wilson et al. (1990) reported that GABA injected into the zona incerta acts on GABA B receptors to inhibit $\mathrm{LH}$ release. In the present study, the hypothesis that this inhibitory effect in the zona incerta is due to inhibition of the stimulatory dopamine system was investigated. It was found that increasing endogenous GABA activity in the whole brain by means of systemic administration of a GABA transaminase inhibitor reduced $\mathrm{LH}$ release and at the same time decreased L-DOPA accumulation and DOPAC concentrations in the zona incerta. These effects in the zona incerta were to some extent specific, as there was no decrease in L-DOPA concentrations in the preoptic area, ventromedial nucleus and arcuate nucleus, or in L-DOPA accumulation in the ventromedial nucleus and arcuate nucleus. The manipulation of GABA activity did not affect expression of tyrosine hydroxylase mRNA in the zona incerta, and thus, similar to progesterone, its effects appear to occur after translation rather than at the level of mRNA.

Another possible dopamine-GABA interaction might be the converse of that discussed above. When progesterone increases LH release, it also stimulates dopamine activity in the zona incerta (MacKenzie et al., 1988; Wilson et al., 1991; this study), which might act to remove the tonic inhibitory effects of GABA from a GnRH system. However, increasing dopamine concentrations in the whole brain increased, rather than decreased, GAD mRNA expression, indicating this interaction is unlikely to occur at transcription. This increase was seen in all the areas examined and indicates that there is an interaction between the dopaminergic and GABAinergic systems that is not specific to a particular area of the hypothalamus.

Therefore, the positive feedback effect of progesterone is probably not mediated via an ovarian steroid-induced increase in dopamine activity leading to removal of the inhibitory effects of a GABAergic system, but rather is a progesterone-induced reduction in GABA activity (Fig. 1). This proposal is supported by the finding that progesterone reduces GAD mRNA expression in the zona incerta (Leigh $e t$ al., 1990). This effect of progesterone removes the inhibitory GABAergic influence on the dopamine system in the zona incerta, which is exerted at post-translational sites.

In summary, the results of the present study confirm that steroids stimulate dopamine activity in the zona incerta and show that oestrogen increases tyrosine hydroxylase mRNA expression, whereas progesterone stimulates tyrosine hydroxylase activity and dopamine release (as indicated by an increase in DOPAC concentrations). In addition, the inhibitory effect of GABA on LH release in the zona incerta may be exerted by decreasing tyrosine hydroxylase activity and dopamine release in this area, and progesterone may act to remove this inhibitory effect of GABA.

V. Kalia was generously supported by the Leverhulme Trust. Gamma-acetylenic GABA was a gift from Merrell Dow Labs, Strasbourg; tyrosine hydroxylase cDNA was a gift from D. Chikaraishi, Tufts University, Boston, USA; GAD67 cDNA was a gift from A. Tobin, UCLA, USA; $\beta$-actin was a gift from Y. Edwards, Galton Laboratories, UCL, London.

\section{References}

Bittencourt JC, Presse F, Arias C, Peto C, Vaughan J, Nahon J-L, Vale W and Sawchenko PE (1992) The melanin-concentrating hormone system of the rat brain: an immuno- and hybridization histochemical characterization Journal of Comparative Neurology 319 218-245

Bjorklund A and Nobin A (1973) Fluorescence histochemical and microspectrofluorometric mapping of dopamine and noradrenaline cell groups in the rat diencephalon Brain Research 51 193-205

Bjorklund A, Lindvall $O$ and Nobin A (1975) Evidence of an incertohypothalamic dopamine neurone system in the rat Brain Research 89 29-42

Bradford MM (1976) A rapid and sensitive method for the quantitation of microgram quantities of protein utilizing the principle of protein dye binding Analytical Biochemistry 72 243-254

Dalton LD and Grossman SP (1982) Responses to dietary adulterations in rats with zona incerta lesions Physiology and Behavior 29 51-60

Day TA, Blessing N and Willoughby JE (1980) Noradrenergic and dopaminergic projections to the medial preoptic area in the rat. A combined horseradish peroxidase/catecholamine fluorescence study Brain Research $193543-548$

Dornan WA, Peterson M, Matuszewich L and Malen P (1991) Ibotenic acidinduced lesions of the medial zona incerta decreases lordosis behaviour in the female rat Behavioral Neuroscience 105 210-214

Eaton MJ, Wagner CK, Moore KE and Lookingland KJ (1994) Neurochemical identification of A13 dopaminergic neuronal projections from the medial zona incerta to the horizontal limb of the diagonal band of Broca and the central nucleus of the amygdala Brain Research 659 201-207

Fox SR, Harlan RE, Shivers BD and Pfaff DW (1990) Chemical characterization of neuroendocrine targets for progesterone in the female rat brain and pituitary Neuroendocrinology 51 276-283

Gunnet JW, Lookingland KJ and Moore KE (1986) Comparison of the effects of castration and steroid replacement on incertohypothalamic dopaminergic neurons in male and female rat Neuroendocrinology 44 269-275

Haglund L, Kohler C, Haarparanta T, Goldstern $M$ and Gustafsson J-A (1984) Presence of NADPH-cytochrome P450 reductase in central catecholaminergic neurons Naturc 307 259-262

Horvath TL, Naftolin F and Leranth C (1993) Luteinizing hormone-releasing hormone and gamma-aminobutyric acid neurons in the medial preoptic area are synaptic targets of dopamine axons originating in anterior periventricular areas Journal of Neuroendocrinology 571-80

James MD, MacKenzie FJ, Tuohy-Jones PA and Wilson CA (1987) Dopaminergic neurons in the zona incerta exert a stimulatory control of gonadotrophin release via D1-dopamine receptors Neuroendocrinology 45 348-355

Kaelber WW and Smith TB (1979) Projections of the zona incerta in the cat with stimulation controls Experimental Neurology 63 177-200

Kendle KE, Patterson JR and Wilson CA (1978) The effect of RMI12,936, a synthetic anti-progestational steroid, on the oestrous cycle and ovulation in the rat fournal of Reproduction and Fertility 53 363-368

Kendrick KM and Baldwin BA (1986) Characterisation of neuronal responses in the zona incerta of the subthalamic region of the sheep during ingestion of food and liquid Neuroscience Letters 63 237-242

Legg CR (1979) Visual discrimination impairments after lesions in zona incerta or lateral terminal nucleus of accessory optic tract Brain Research 177 $461-478$

Leigh AJ, Carter ND, Horton R, Silverlight JJ and Wilson CA (1990) Ovarian steroid regulation of glutamic acid decarboxylase gene expression in individual hypothalamic nuclei Journal of Neuroendocrinology $2433-438$

Lewis EJ, Tank W, Weiner N and Chikaraishi DM (1983) Regulation of tyrosine hydroxylase mRNA by glucocorticoid and cyclic AMP in a rat 
pheochromocytoma cell line; isolation of a cDNA clone for tyrosine hydroxylase mRNA Journal of Biological Chemistry 258 14 632-14 637

MacKenzie FJ, Hunter AJ, Daly C and Wilson CA (1984) Evidence that the dopaminergic incerto-hypothalamic tract has a stimulatory effect on ovulation and gonadotrophin release Neuroendocrinology 39 289-295

MacKenzie FJ, James MD and Wilson CA (1988) Changes in dopamine activity in the zona incerta (ZI) over the rat oestrous cycle and the effect of lesions of the ZI on cyclicity: further evidence that the incerto-hypothalamic tract has a stimulatory role in the control of LH release Brain Research $\mathbf{4 4 4}$ 75-83

May PJ, Sun W and Hall WC (1997) Reciprocal connections between the zona incerta and the pretectum and superior colliculus of the cat Neuroscience $\mathbf{7 7}$ 1091-1114

Mihailoff GA (1995) Orthograde axonal transport studies of projections from the zona incerta and pretectum to the basilar pontine nuclea in the rat Journal of Comparative Neurology 360 301-318

Moga MM and Moore RY (1996) Putative excitatory amino acid projections to the suprachiasmatic nucleus in the rat Brain Research 743 171-177

Morrell JI, Rosenthal MF, McCabe JT, Harrington CA, Chikaraishi DM and Pfaff DW (1989) Tyrosine hydroxylase mRNA in the neurons of the tuberoinfundibular region and zona incerta examined after gonadal steroid hormone treatment Molecular Endocrinology 3 1426-1433

Nicolelis MAL, Chapin JK and Lin RCS (1995) Development of direct GABAergic projections from the zona incerta to the somatosensory cortex of the rat Neuroscience 64 609-631

Oertel WH, Tappaz ML, Berod A and Mugnaini E (1982) Two-color immunohistochemistry for dopamine and GABA neurones in rat substantia nigra and zona incerta Brain Research Bulletin $9463-474$

Palkovits M (1973) Isolated removal of hypothalamic or other brain nuclei of the rat Brain Research 59 449-450

Paxinos G and Watson C (1982) The Rat Brain in Stereotaxic Coordinates Academic Press, Sydney

Ricardo JA (1981) Efferent connections of the subthalamic region in the rat. II. The zona incerta Brain Research $21443-60$

Ross CA, Ruggiero DA, Meeley MP, Park DH, Job TH and Reis DJ (1984) A new group of neurons in the hypothalamus containing phenylethanolamine$\mathrm{N}$-methyltransferase (PNMT) but not tyrosine hydroxylase Brain Research $306349-353$

Sakurai T, Amemiya A, Ishii M et al. (1998) Orexins and orexin receptors: a family of hypothalamic neuropeptides and $G$ protein-coupled receptors that regulate feeding behaviour Cell 92 573-585
Sanghera MK, Anselmo-Franci J and McCann SM (1991a) Effect of medial zona incerta lesions on the ovulatory surge of gonadotrophins and prolactin in the rat Neuroendocrinology $54433-438$

Sanghera MK, Grady S, Smith W, Woodward DJ and Porter JC (1991b) Incertohypothalamic A13 dopamine neurons: effects of gonadal steroids on tyrosine hydroxylase Neuroendocrinology 53 268-275

Sar M (1984) Estradiol is concentrated in tyrosine hydroxylase containing cells Science $223938-940$

Shammah-Lagnado SJ, Negrao N and Ricardo JA (1996) Afferent connections of the zona incerta: a horseradish peroxidase study in the rat Neuroscience 15 109-134

Shoemaker WJ and Schlumpf M (1977) Diencephalic dopamine cell groups: correlations with endocrine status. In Advances in Biochemical Psychopharmacology Vol. 16 pp 359-367 Eds E Costa and GL Gessa. Raven Press, New York

Shughrue PJ, Lane MC and Merchenthaler I (1997) The comparative distribution of oestrogen receptor $\alpha$ and $\beta$ mRNA in the rat central nervous system Journal of Comparative Neurology 388 507-525

Tian Y, Lookingland KJ and Moore KE (1991) Contribution of noradrenergic neurones to 3,4-dihydrophenyl acetic acid concentrations in the regions of the rat brain containing incerto hypothalamic dopaminergic neurones Brain Research 555 135-140

Tonelli L and Chiaraviglio E (1995) Dopaminergic neurones in the zona incerta modulates ingestive behavior in rats Physiology and Behaviour 58 725-729

Unda R, Brann DW and Makesh UB (1995) Progesterone suppression of glutamic acid decarboxylase (GAD67) mRNA levels in the pre-optic area: correlation to the luteinizing hormone surge Neuroendocrinology 62 562-570

Wagner CK, Eaton MJ, Moore KE and Lookingland KJ (1995) Efferent projections from the region of the medial zona incerta containing $\mathrm{A} 13$ dopaminergic neurons. A PHA-L anterograde tract-tracing study in the rat Brain Research 677 229-237

Wilkes MM, Kobayashi RK, Yen SSC and Moore RY (1979) Monoamine neuron regulation of LRF neurons innervating the organum vasculosum laminae terminalis and median eminence Neuroscience Letters 13 41-46

Wilson CA, James MD and Leigh AJ (1990) Role of gamma-aminobutyric acid in the zona incerta in the control of luteinizing hormone release and ovulation Neuroendocrinology 52 354-360

Wilson CA, James MD, Grierson IP and Hole DR (1991) Involvement of catecholaminergic systems in the zona incerta in the steroidal control of gonadotrophin release and female sexual behaviour Neuroendocrinology 53 $113-123$ 